\section{Could Superior Mesenteric Artery Angle Measurement Predict the Course of Renal Symptoms in Children With Nutcracker Syndrome?}

To the Editor: We read with interest the article by Fitoz et al. ${ }^{1}$ They reported that superior mesenteric artery (SMA) angle measurement and upright position imaging might be useful adjunct parameters in the diagnosis of nutcracker syndrome.

We previously reported that nutcracker syndrome might resolve spontaneously by an increase of the body mass index during childhood. ${ }^{2}$ In this study, all 20 patients showed a decrease in the peak velocity ratio of the left renal vein (LRV) at follow-up renal Doppler sonography, but 5 of them still had persistent hematuria. Although not mentioned in that study, we speculate that the course of renal symptoms might be different according to the various causes of nutcracker syndrome, such as renal ptosis or abnormal branching of the SMA from the aorta. Although the increase of the vessel diameter and visceral fat pad by physical development during childhood might partly relieve aortomesenteric compression of the LRV, the anatomic severity of a narrow SMA angle or position-dependent changes might influence the course of renal symptoms in children with nutcracker syndrome.
Therefore, we think that curiosity regarding the pathogenesis of persistent renal symptoms (hematuria or proteinuria) might be resolved by the measurement of the SMA angle and upright position imaging at follow-up.

$$
\begin{array}{r}
\text { Jae Il Shin, MD } \\
\text { Jae Seung Lee, MD } \\
\text { Department of Pediatrics } \\
\text { Institute of Kidney Disease } \\
\text { Yonsei University College of Medicine } \\
\text { Severance Children's Hospital } \\
\text { Seoul, Korea }
\end{array}
$$

\section{References}

1. Fitoz S, Ekim M, Ozcakar ZB, Elhan AH, Yalcinkaya F. Nutcracker syndrome in children: the role of upright position examination and superior mesenteric artery angle measurement in the diagnosis. J Ultrasound Med 2007; 26: $573-580$.

2. Shin JI, Park JM, Lee SM, et al. Factors affecting spontaneous resolution of hematuria in childhood nutcracker syndrome. Pediatr Nephrol 2005; 20:609-613.

\section{Reply}

To the Editor: We thank Drs Shin and Lee for their supporting comments on our recent article. We agree with them that the potential benefits of follow-up Doppler sonographic investigations in our study subjects along with evaluation of changes in the body mass index would help differentiate pathogenetic possibilities in nutcracker syndrome. 